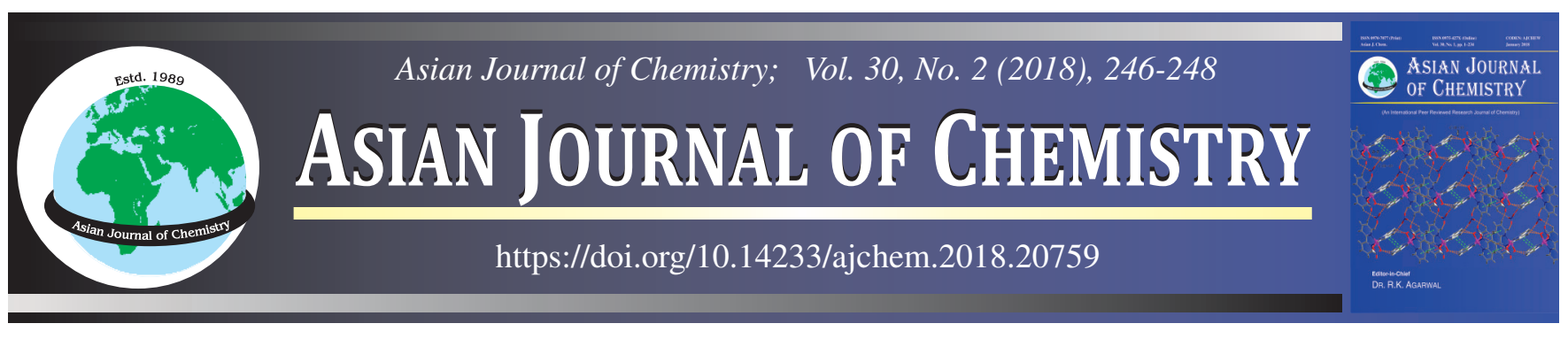

\title{
Optimization of Green Methods for Extraction of Polysaccharides from Fruits of Pithecellobium dulce
}

\author{
S. PreEthi and A. Mary SARAL*
}

Department of Chemistry, School of Advanced Sciences, Vellore Institute of Technology, Vellore-632 014, India

*Corresponding author: E-mail: amarysaral@vit.ac.in

Received: 4 May 2017;

Accepted: 9 November 2017;

Published online: 31 December 2017;

AJC-18684

\begin{abstract}
This study was conducted to develop a rapid, simple microwave assisted extraction method for the quantification of polysaccharide contents from Pithecellobium dulce pods utilizing fundamental principles of Green Chemistry. The plant is reported to be a folk remedy for ear and tooth ache. It also acts as an emollient, anodyne and larvicidal in folk medicine. As the fruit is liked by common people of Vellore city and throughout the country, a scientific investigation on the edible part of the plant was initiated in our laboratory. Optimization of extraction procedures using modern technologies significantly reduces the quantity of solvent consumed and waste generated during an extraction process. The optimal conditions were determined as follows: $50 \%$ microwave power, an irradiation time of 3 min and a solidliquid ratio of $1: 20 \mathrm{~g} \mathrm{~mL}^{-1}$. Analysis of variance showed that the contribution of the quadratic model was significant for the responses. Under the optimum conditions, the extraction yield of crude polysaccharides was $63.7 \%$. This paper outlines a systematic approach for optimization of an extraction procedure for isolation of potential polysaccharide. The extracts were tested to determine the total polysaccharide content by phenol sulphuric acid method.
\end{abstract}

Keywords: Pithecellobium dulce, Polysaccharide, Microwave assisted extraction.

ᄂ $-\ldots-\ldots-\ldots-\ldots-\ldots-\ldots-\ldots-\ldots-\ldots-\ldots-1$

\section{INTRODUCTION}

Pithecellobium dulce is locally called as manila tamarind belongs to the family Mimosaceae. It is a small to medium sized evergreen spiny tree height which grows up to 18-20 m, native of tropical America and cultivated through the plains of India and Andaman [1]. The seed oil was used as an edible and also for manufacturing soap [2]. The bark was reported to have astringent in dysentery, febrifuge and it contains upto 37 $\%$ of tannins. Polyphenols from the bark extract possess antivenomous activity [3]. The seed are found to contain steroids, saponins, glycosides, lipids and polysaccharides which are reported to have antidiabetic and antioxidant activity [4]. Afzelin (kaemperol-3-O- $\alpha$-L-rhamopyranoside) was isolated from the leaves of Pithecellobium dulce which have antimycobacterial property. The leaves also reported to have antiinflammatory, analgesic, antioxidant and antidiabetic activities [5-8]. The Pithecellobium dulce fruits have also been studied for anti-inflammatory activity due to saponin content, free radical scavenging and gastro-protective, antidiabetic and hepatoprotective effects [9-11]. The aqueous extract of flowers reported to have cardioprotective activity [12]. In present study, we investigated the optimization parameters with reference to solvent choice, and extraction methods. In the literature, we found the choice of solvent depends on the active compounds due to which the pharmacological activities were aimed $[8,9]$. But in the present study, we concentrate on polysaccharide as bioactive compound and hence, the choice of solvent, extraction method and other experimental parameters are discussed.

\section{EXPERIMENTAL}

Fresh fruits of Pithecellobium dulce were collected from Vellore district, India and was authenticated (PARC/2015/ 3107) by Dr. Jayaraman, National Anatomy Research Centre, Chennai, India. The ripened fruits were dried at room temperature under shade and powdered using mechanical grinder. The powder is stored in a refrigerator for further use.

\section{Sample preparation}

Soxhlet method: About $50 \mathrm{~g}$ of dried powdered sample of Pithecellobium dulce pods was extracted with ethanol, methanol and water, respectively. The total time of extraction was $5 \mathrm{~h}$. Then the obtained extract was concentrated under reduced pressure and evaporated to dryness.

Immersion method: About $50 \mathrm{~g}$ dried powdered fruit material was taken and extracted with $200 \mathrm{~mL}$ of ethanol, methanol and water, respectively. The total time of extraction was $24 \mathrm{~h}$. The obtained extract was then concentrated under reduced pressure and evaporated to dryness. 
Microwave assisted extraction: About $1 \mathrm{~g}$ of dried powdered sample was weighed, placed into a conical flask and solubilized using different amounts of solvent $(15-30 \mathrm{~mL})$. Some experiments were carried out using water as solvent, the other ones with ethanol. The extraction was performed under various conditions. The conical flask was placed in the oven and put under magnetic stirring. It was exposed to microwave radiations at different powers [210 (30\%)-350 (50\%)-560 W (80\%)], for the selected irradiation time (1-3 min). After microwave heating, the solution was allowed to cool down to room temperature and filtered using Whatman filter paper. Finally, the volume of the filtered extract was reduced using hot plate and a water bath.

After extraction and heating, the wet extract was dried until its weight becomes constant and weighed. The yield of extraction was calculated using eqn. 1 :

$$
\text { Yield }(\%)=\frac{\mathrm{m}}{\mathrm{m}_{\mathrm{o}}} \times 100
$$

whereas, $m_{o}$ is the weight of the initial dried powdered sample, and $m$ is the the weight of final dried extract.

Preliminary phytochemical screening: Crude extract of Pithecellobium dulce was dissolved in ethanol and subjected to the phytochemical tests. The study was carried out by using standard procedures described by Harborne [13].

Determination of total phenolic content: The total phenolic content of Pithecellobium dulce fruit extract was determined by using Folin-Ciocalteau reagent. Gallic acid is used as a reference standard for plotting calibration curve. The total phenolic content was expressed as $\mathrm{mg} / \mathrm{g}$ gallic acid equivalent of dry extract [14].

Determination of total flavonoid content: The total flavonoid content of Pithecellobium dulce fruit extract was determined using colorimetric aluminium chloride method. Quercetin is used as a reference standard for plotting calibration curve. It is expressed as $\mathrm{mg} / \mathrm{g}$ quercetin equivalent of dry extract [15].

Total carbohydrate estimation: The total carbohydrate assay of Pithecellobium dulce fruit extract was determined by colorimetric phenol sulphuric acid method with slight modification. Dextrose is used as a reference standard. It is expressed as $\mathrm{mg} / \mathrm{g}$ dextrose equivalent of dry extract [16].

\section{RESULTS AND DISCUSSION}

Conventional method: The powdered Pithecellobium dulce pods was extracted with aqueous, methanol and ethanolic solvents using two different conventional methods, i.e., immersion and soxhlet extraction.

Soxhlet method: After $5 \mathrm{~h}$ extraction, the final yield of extraction obtained was $54.8 \%$ for water, $32.7 \%$ for methanol and $28.4 \%$ ethanol, respectively. In the continuous soxhlet extraction the better solvent was water when compared to other two solvents like methanol and ethanol. Conventional method is good for yield but it has time constraint.

Immersion method: After $24 \mathrm{~h}$ of extraction, the final yield obtained was $19.8 \%$ for methanol, $15.4 \%$ for ethanol. In immersion method, water is not a good solvent for extraction due to microbial contamination.

\section{Microwave assisted extraction}

Optimization of the solvent: The final yield of extraction obtained was $63.7 \%$ for water, $55.2 \%$ for methanol and $42.6 \%$ for ethanol. The extraction yield using aqueous solvent was significantly greater than the extraction yield using methanol and ethanol. Hence, the optimization was done with water as a solvent.

Optimization of microwave power: The extraction efficiency was improved by raising microwave power from 210 to $350 \mathrm{~W}$. In fact, the accelerated extraction of pectin by increasing microwave power is related to the direct effects of microwave energy on the plant materials [17]. Microwave radiation loosens the cell wall matrix and the skin tissues are rapidly and extensively opened up by the microwave [18]. This will lead to increased interactions between extracting agent and source material in extraction process. Fig. 1 shows the yield of different power with different irradiation time. The optimized power is $350 \mathrm{~W}$.

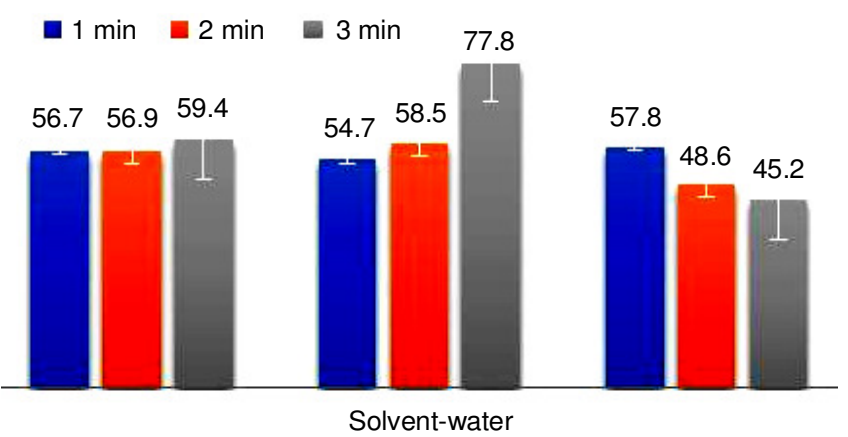

Fig. 1. Optimization of microwave power

Optimization of irradiation time: Irradiation time is one of the key factors affecting the yield of extraction [19]. From the results, it is observed that the efficiency was also improved by raising time from 1 to $3 \mathrm{~m}$ in the case of the series at 210 and $350 \mathrm{~W}$. Concerning the last one, the microwave power was too high and the solvent (water) was boiled, hence a lower yield of extraction. Fig. 1 shows the optimization of irradiation time of the extraction. The optimized irradiation time is $3 \mathrm{~min}$.

Optimization of solid-liquid ratio: Fig. 2 shows the optimization of solid liquid ratio. The optimal solid-liquid ratio is $1: 20 \mathrm{~g} \mathrm{~mL}^{-1}$ for $0.5 \mathrm{~g}$ of dry powder in $10 \mathrm{~mL}$ of water.

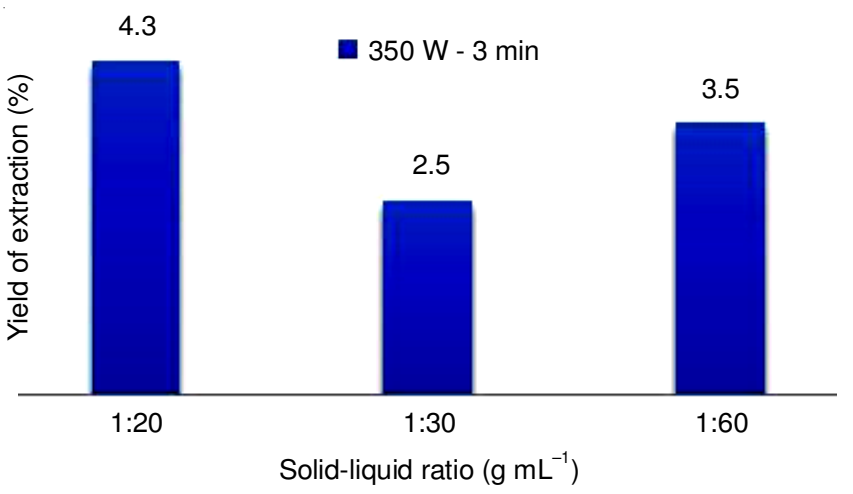

Fig. 2. Optimization of solid-liquid ratio

Preliminary phytochemical analysis: Phytochemical screening of microwave assisted water extract from Pithecellobium dulce by qualitative studies shows the presence of phenols, flavonoids, saponins and carbohydrates. The presence of other constituents is not detected in this extract (Table-1). 


\begin{tabular}{clc}
\hline \multicolumn{3}{c}{ TABLE-1 } \\
\multicolumn{3}{c}{ PHYTOCHEMICAL SCREENING OF } \\
\multicolumn{3}{c}{ MICROWAVE ASSISTED AQUEOUS EXTRACT } \\
\hline S. No. & \multicolumn{1}{c}{ Tests } & Aqueous \\
\hline 1 & Alkaloids & - \\
2 & Phenols and Tannins & ++ \\
3 & Flavonoids & ++ \\
4 & Carbohydrate & ++ \\
5 & Saponins & + \\
6 & Steroids & + \\
7 & Terpernoid & + \\
\hline
\end{tabular}

Note: + High, ++ Higher, +++ Highest

Total phenolic content: Total phenolic content was estimated using Folin-Ciocalteau reagent. Water extract of Pithecellobium dulce pods contain $6.5 \mathrm{mg} / \mathrm{g}$ GAE.

Total flavonoid content: Total flavonoid content was estimated using colorimetric aluminium chloride method. Aqueous extract of $P$. dulce contains $2.89 \mathrm{mg} / \mathrm{g}$ equivalence of quercetin.

Total carbohydrate content: Total carbohydrate content was estimated by phenol sulphuric acid method. Aqueous extract of $P$. dulce contains $34.83 \mathrm{mg} / \mathrm{g}$.

\section{Conclusion}

Compared to the conventional method, microwave method provide good yield. The percentage yield of ethanolic extract is $42.6 \%$, methanol extract is $58.2 \%$ and aqueous extract is $63.7 \%$. The optimal parameters were found to be water as solvent, a microwave power of $50 \%$, an irradiation time of 3 min and a solid-liquid ratio of 1:20 $\mathrm{g} \mathrm{mL}^{-1}$. As regards the quantitative analysis, aqueous extract contains higher number of polysaccharides than phenol and flavonoids. As the crude extracts reported to contain good number of polysaccharides, this could be explored in detail for its pharmacological activities.

\section{ACKNOWLEDGEMENTS}

The authors are grateful to Sophisticated Instrument Facility, School of Advanced Sciences, Vellore Institute of Technology, Vellore, India for providing necessary laboratory facilities and support.

\section{REFERENCES}

1. M. Sugumaran and T. Vetriselvan, Pharm. Rev., 6, (2008).

2. P. Pithayanukul, P. Ruenraroengsak, R. Bavovada, N. Pakmanee, R. Suttisri and S. Saen-oon, J. Ethnopharmacol., 97, 527 (2005); https://doi.org/10.1016/j.jep.2004.12.013.

3. D.M. Nagmoti, P.S. Kothavade, V.D. Bulani, N.B. Gawal and A.R. Juvekar, Eur. J. Integr. Med., 7, 263 (2015); https://doi.org/10.1016/j.eujim.2015.01.001.

4. M. Sugumaran, T. Helvan and D. Venkapayya, Anc. Sci. Life, 25, 92 (2006).

5. S.D. Katekhaye and D.M. Nagmoti, Phytopharmacology, 4, 123 (2013).

6. V.S. Mule, V.H. Potdar, S.D. Jadhav and J.I. Disouza, Res. J. Pharmacol. Pharmacodyn., 3, 27 (2011).

7. B. Edwin, M. Amalanathan and I.H. Joe, Spectrochim. Acta A Mol. Biomol. Spectrosc., 96, 10 (2012);

https://doi.org/10.1016/j.saa.2012.04.062.

8. J. Megala and A. Geetha, Food Chem., 121, 1120 (2010); https://doi.org/10.1016/j.foodchem.2010.01.059.

9. J. Megala and A. Geetha, J. Ethnopharmacol., 142, 415 (2012); https://doi.org/10.1016/j.jep.2012.05.011.

10. J. Megala and A. Geetha, Pharmacologyonline, 2, 353 (2011).

11. S. Pradeepa, S. Subramanian and V. Kaviyarasan, Int. J. Herbal Med., 1, 21 (2013).

12. R. Bhavani, R. Shobana and S. Rajeshkumar, Int. J. Pharm. Res., 6, 82 (2014).

13. J.B. Harborne, Phytochemical Methods, Chapman Hall, London, pp. 60-66 (1998)

14. J.P. Philip, G. Madhumitha and S.A. Mary, Asian Pac. J. Trop. Med., 4, 457 (2011); https://doi.org/10.1016/S1995-7645(11)60125-9.

15. S.R. Suseem and A.M. Saral, Int. J. Drug Develop. Res., 5, 174 (2013).

16. M.B. Hall, Anim. Feed Sci. Technol., 185, 94 (2013); https://doi.org/10.1016/j.anifeedsci.2013.06.008.

17. C. Javanmardi and Stushnoff, Food Chem., 83, 547 (2003); https://doi.org/10.1016/S0308-8146(03)00151-1.

18. J. Berovic, J. Habijanie, I. Zore, B. Wraber, D. Hodzar, B. Boh and F. Pohleven, J. Biotechnol., 103, 77 (2003); https://doi.org/10.1016/S0168-1656(03)00069-5.

19. K.A. DuBois, K.A. Gilles, J.K. Hamilton, P.A. Rebers and F. Smith, Anal. Chem., 28, 350 (1956); https://doi.org/10.1021/ac60111a017. 